\title{
Análise de parâmetros hematimétricos e bioquímicos em equinos Quarto de Milha atletas pré e pós-treinamento
}

Guilherme Barbosa Costa;, Aulo Henrique Araujo, Guilherme Henrique Rocha, Izabela Puerchi Ribeiro, Isadora Helena Melo, Mateus Pradela Castalgini, Mariana Reato Nascimento, Daniel Paulino Junior

*Autor correspondente

e-mail: guibc14@hotmail.com

\section{Resumo}

Um aspecto predominante atualmente é que o cavalo tem se destinado mais ao esporte do que ao trabalho no campo. Existem diferentes modalidades esportivas, com variados níveis de exigências, fazendo-se necessário um planejamento adequado do treinamento a fim de evitar lesões futuras ao equino atleta. Neste trabalho, buscou-se analisar os parâmetros hematimétricos e bioquímicos de equinos submetidos a atividades físicas de alto rendimento. Foram avaliados 13 equinos da raça Quarto de Milha, com idades variadas de 5 a 15 anos, peso entre 350 a 550 quilos, submetidos regularmente a atividades físicas, como prova de explosão e agilidade. Estas foram realizadas às terças-feiras, quintas-feiras e sábados, por um período de 2 h e 15 min, com intervalos de 10 a 15 minutos por animal na pista, a qual era composta de areia e com comprimento de $600 \mathrm{~m}$ e largura de $60 \mathrm{~m}$. As coletas de dados para análise foram realizadas pré e pós-exercício, durante 60 dias - T0, T15, T30, T45, T60 -, da seguinte forma: a equipe de coleta chegava ao local 2 horas antes do início dos treinamentos para que fossem medidos os parâmetros dos animais no pré-treino (as coletas eram realizadas na seguinte sequência: retirada de sangue para hemograma, CK, glicose e lactato); a equipe esperava o início dos treinamentos, e assim que os animais eram liberados de seus exercícios, eram coletadas as análises do pós-treino. Em relação aos resultados das variáveis hematimétricas, foi possível observar que a média no pós-treino das hemácias em todas as coletas teve um aumento percentual de 35\% em relação ao pré-treino, variando de $10,6 \pm 1 \times 10^{6}$ para $15 \pm 1,2 \times 10^{6}$, o que nos leva a seguinte hipótese: considerandose que durante o exercício os equinos fazem a contração esplênica, mais hemácias são ejetadas na circulação para que haja uma distribuição de oxigênio para os músculos de forma rápida, para a produção de ATP e para estes trabalharem mais, visto que a hemoglobina é importante carregador de oxigênio. Já no leucograma, foi possível observar linfocitose, mas sem alteração nos leucócitos totais. Nos exames de CK, observa-se que os cavalos analisados tiveram uma variação de 141,5 \pm 39 UI/L no pré-T0 para 248,1 \pm 160 UI/L no 
pré-T60. Já no pós-T0, obteve-se 280,8 \pm 218 UI/L, sendo esta variável alterada no pós-T60 com valor de $296,9 \pm 102,9 \mathrm{UI} / \mathrm{L}$, atingindo aumento de aproximadamente $43 \%$ pré e $5,5 \%$ pós. Os padrões de lactato estão entre 1,11 e 1,78 Mmol/L nos cavalos submetidos ao exercício. Pode-se observar no pré-T0 valor de 3,4 \pm 0,5 Mmol/L e no pós, valor de 17,8 $\pm 3,4 \mathrm{Mmol} / \mathrm{L}$. Já no T60, observa-se pré de 1,15 \pm 0,3 Mmol/L e pós de 14,84 $\pm 5,8 \mathrm{Mmol} / \mathrm{L}$, tendo uma variação de diminuição de $63 \%$ no pré e de $17 \%$ no pós. Ao decorrer dos treinamentos, com o aumento da intensidade exigida, a grande maioria da glicose é consumida no processo aeróbico quando forçamos o aumento da intensidade a níveis de alto desempenho, e a troca oxigênio se torna insuficiente quando se inicia o processo anaeróbico. Podemos observar no pré-T0 que níveis séricos de glicose se mantiveram $90 \pm 10,3 \mathrm{mg} / \mathrm{dl}$, variando no pós para 127,3 $\pm 23,2 \mathrm{mg} / \mathrm{dl}$. Já no T60, a variável foi de $84,6 \pm 10,8 \mathrm{mg} / \mathrm{dl}$ no pré e de $103,5 \pm 24,2 \mathrm{mg} / \mathrm{dl}$ no pós, tendo um percentual de queda de $6 \%$ no pré e de $19 \%$ no pós. Observa-se também que alterações na glicemia foram relativamente semelhantes as do lactato, mostrando uma adaptação do animal ao treinamento e a opção de uma via alática "CK" para geração de energia para a atividade alto desempenho. Após análise descritiva, conclui-se que o acompanhamento dos cavalos submetidos a esportes alto desempenho é de extrema importância, pois proporciona um melhor cuidado com os animais, evitando possíveis lesões por esforço, além de auxiliaro o médico veterinário no diagnóstico precoce, melhorando e prolongando a vida atlética dos animais.

Palavras-chave: Cavalo. Creatina quinase. Esporte equestre. 